\title{
Progreso en el arte y ciencia dental y bucal. Del ingenio a la tecnología
}

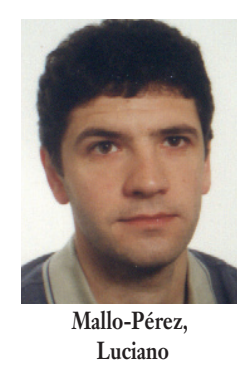

Progress in the dental art and science. From talent to technologu

\section{Mallo-Pérez, Luciano* Sanz-Serrulla, Javier*}

*Doctor en medicina y cirugía. Médico-estomatólogo.
Resumen: Los avances en las artes y ciencias odontológicas han sido espectaculares, sobre todo en el último medio siglo. Los autores analizan tal evolución intentando descubrir qué parte del progreso corresponde a las novedades en el conocimiento científico básico y cuánto es fruto de la evolución técnica y tecnológica. Con este fin, estudian separadamente cada una de las especialidades odontológicas, bajo un punto de vista histórico y objetivo. Los autores concluyen que la mayor parte del progreso en las disciplinas dentales es atribuible al desarrollo tecnológico, habiéndose modificado muy poco las bases conceptuales de la odontología.

Palabras clave: Odontología. Evolución histórica. Avance científico. Avance tecnológico.

Abstract: The evolution of the dental art and science has been spectacular in the past last half century. The authors of this article analysed this evolution, trying to discriminate how much of the evolution was due to basic scientific knowledge and how much corresponded to technic development. So, the authors studied separately each odontologic speciality from an objective and historical point of view, and concluded that most of the progress in dental disciplines was due to technological improvement, while conceptual bases had been modified very little.

Key words: Dentistry. Historic evolution. Scientific evolution. Technologic development.

BIBLID [1138-123X (2004)9:6; noviembre-diciembre 613-736]

Mallo-Pérez L, Sanz-Serrulla J. Progreso en el arte y ciencia dental y bucal. RCOE 2004;9(6):667-681. 
No importa el problema, importa la solución.

(AC,AR).

\section{Introducción}

Está demostrado que el desarrollo de las ciencias y los conocimientos que dependen de un modo más 0 menos directo de los avances tecnológicos sigue un ritmo de progresión geométrico. Así, podemos asegurar que, sin duda, se ha progresado mucho más en los últimos 50 años que en el resto de los miles de evolución humana en campos como la ingeniería industrial, la inteligencia artificial o los materiales deportivos. Por lo que se refiere a la medicina, es frase acuñada que "se ha avanzado más en los últimos 25 años que en los últimos 25 siglos", justamente desde el comienzo de la «medicina racional» en Crecia; en buena medida se puede afirmar 10 mismo para la odontología y la estomatología. La capacidad para afrontar compromisos odontológicos se ha multiplicado y, sobre todo, se ha universalizado. En la actualidad se puede dar solución a un número importantísimo de problemas bucodentales, muchos de ellos imposibles o impensables de solventar hace unas pocas décadas, y además se puede hacer de un modo previsible, en casi cualquier lugar de la geografía de los países occidentales y a un costo, en la mayoría de los casos, asumible.

El método científico es el paradigma de la evolución científica y de la ciencia en sí. Está descrito hace varias centurias y es un sistema coherente, genérico y adaptable a muchas situa- ciones y posibilidades; es tan válido para la ingeniería como para la agricultura, la física o la medicina. Actualmente está de moda lo que ha venido en llamarse la medicina (y por extensión la odontología) basada en la evidencia, que no es otra cosa que el espacio de encuentro entre el sentido común, el método científico y la objetividad; el eslabón inferior en la cadena de la evidencia lo constituyen las recomendaciones personales -incluidas las ilustres e ilustrísimas- y los criterios individuales'. Resulta paradójico que ambas sean empleadas cotidianamente, hasta constituir el modo de actuar habitual de gran cantidad de dentistas.

Un importante número de profesionales sabe "hacer las cosas», incluso "las hace bien». Otro aspecto bien diferente es que sepa el motivo por el que las hace de esa manera, convirtiendo una técnica, resultado último de una cadena científica de base, en un mero acto, equiparable, salvando las distancias, a cambiar una rueda de un automóvil o a reparar el mecanismo de un reloj carrillón. Es muy común en las conversaciones informales de cursos, congresos y otras actividades científicas, escuchar, incluso de los primeros espadas, sentencias del tipo: «lo hago y funciona, pero no tengo ni idea del por qué» (a veces con la coletilla «ni me importa»), "pues aunque no tenga base, en mis manos funciona», etc. Esta realidad nos sitúa cerca del empirismo, al tiempo que nos aleja de lo que debe ser la ciencia.

De ningún modo se puede ni debe entender la disciplina bucodental aislada de la medicina. Independientemente de la cambiante relación administrativa y docente entre ambas, que se remonta a más de un siglo y medio y se mantiene hoy en día, es evidente que la dentistería se ocupa de los aspectos que guardan relación con la boca (estudio de sus componentes en estado sano y enfermo, y las formas de enfermar, curar y prevenir), exactamente igual que otras especialidades lo hacen con un órgano, sistema o aparato determinado. Pero con diferencias. El acto médico por definición es el diagnóstico, del cual se deriva la terapéutica correspondiente. En la profesión dental el centro neurálgico es la terapéutica, siendo el resto de factores, aunque importantes, complementarios. Y esto es así desde una cuádruple perspectiva: a/ por un lado la enorme mayoría de los pacientes identifican casi exclusivamente la calidad del acto odontológico con el alivio de los signos y síntomas, objetivos estéticos y durabilidad; b/ los dentistas en las escuelas y facultades aprenden antes cómo se hace que por qué se hace; la mayoría de los cursos de formación continuada son técnicos; un número importantísimo (probablemente la mayoría) de los dentistas no cobran por las consultas y primeras visitas, incluso es un reclamo publicitario habitual; c/ la industria aporta cada día nuevas soluciones técnicas y d/ desde el punto de vista legal comienzan a exigirse resultados y no medios como en el contrato médico convencional. Históricamente los dentistas eran terapeutas con cuerpo doctrinal mixto, barberos-dentistassangradores, y muy próximos en su origen a los cirujanos. Tanto los cirujanos como los dentistas independizaron su quehacer tanto en cuanto se juntaron con los médicos, hasta el punto que nadie concibe en la actua- 
lidad un cirujano que no sea médico y muchos lo mismo con el dentista ${ }^{2}$. Esta última circunstancia es una discusión periódica y centenaria, con largos debates y cambios pendulares; un campo de política universitaria y de intereses encontrados, bien lejos de los objetivos de este artículo.

«No toda ciencia es científica. El que fabricó las hachas de sílex en el periodo chelense, carecía de ciencia y sin embargo creó una técnica. La China llegó a un alto grado de tecnicismo sin sospechar lo más mínimo la existencia de la física. Sólo la técnica moderna tiene raíz científica y de esa raíz le viene su carácter específico, la posibilidad de un ilimitado progreso. Las demás técnicas -mesopotámica, nilota, griega, romana, oriental- se estiraron hasta un punto de desarrollo que no pudieron sobrepasar, y apenas lo tocaron, comenzaron a retroceder en una lamentable involución». Esta cita, de alguien tan poco sospechoso como Ortega y Gassett ${ }^{3}$, aún siendo de 1938, conserva toda su vigencia e ilustra perfectamente nuestro objetivo. El progreso tecnológico nos ha brindado enormes posibilidades $y$, aunque es imprescindible, también nos ha hecho más dependientes y probablemente menos ingeniosos. Reducir la cuestión a números es imposible, pero creemos asumible hacer una aproximación al desafío. Ésta.

\section{Objelivo}

Estudiar la evolución de la odontología y sus especializaciones desde un punto de vista científico y con una perspectiva histórica e intentar separar lo que en la evolución del arte y ciencia dental corresponde al progreso en el conocimiento científico de la evolución técnica y tecnológica.

\section{Algunas consideraciones previas}

Los autores intentan ofrecer una visión, por lo tanto contrastable y objetiva, de la evolución histórica de la ciencia, de la técnica y de la tecnología odontológica, intentando alejarse en todo lo posible de la opinión, subjetiva. Somos conscientes de que esto no siempre es posible de conseguir, aunque hemos intentado que así fuese en todo momento.

Queremos expresar el respeto que nos merece tanto la profesión dental, como sus practicantes, entre los cuales nos encontramos.

Sabemos que es imposible resumir en unas pocas páginas lo que en la literatura especializada ocupa muchos millones, por lo cual asumimos que cualquier interpretación es incompleta y parcial; hemos intentado encarecidamente que este sesgo haya sido el menor posible.

La estomatología y la odontología tienen un significado etimológico perfectamente diferenciado ${ }^{4}$; las definiciones legales ${ }^{5}$ más que aclarar, confunden por farragosas y llenas de palabras y defectos como carentes de claridad, y, en la práctica, la actividad de odontólogos y estomatólogos es tan similar que es superponible. Lejos de cualquier polémica, a lo largo del texto empleamos indiferentemente los términos odontólogo, estomatólogo y dentista.

Algo parecido puede decirse del término especialista. Si bien muchos emplean las palabras especialista, superespecialista o subespecialista, su validez legal parece ser cuestionable. No obstante es innegable la existencia de especializaciones odontológicas, incluso dentro de ellas mismas. Por estos motivos, utilizamos estos términos repetidamente en el texto.

Los adverbios "siempre» y "nunca», "todo" y "nada" carecen de significado absoluto en amor y medicina. Su empleo a lo largo del texto se tomará con esta precaución.

\section{Fundamentación}

\section{histórica: el predominio de la tecnología sobre la ciencia odontológica. ¿ilna realidad eterna?}

Remontándose a los últimos años del siglo XIX y comienzos del siguiente, los doctores Carranza y Shklar ${ }^{6}$ recuerdan que la práctica de la odontología americana estaba orientada principalmente hacia la tecnología, mientras que la germana tenía un fondo científico más sólido, lo cual no hace sino corroborar un hecho para nosotros evidente: la existencia de dos orientaciones en la odontología en aquellos primeros momentos en que la odontología se consolidaba como disciplina independiente. Pero andando el tiempo, y al contrario de lo que cabría esperarse en una rama de la medicina, la balanza odontológica caería del lado del platillo de la tecnología por el mayor peso de sus contribuciones. 
Esta divergencia en la manera de enfocar por un lado el arte y por otro la ciencia dental quedaron reflejados en los currículos de las escuelas e institutos de odontología aparecidos en ambos países y en otros que asimilaron ambos modelos. Pero esta diferencia tenía también un importante componente comercial. En América muchos aparatos y materiales fueron patentados, por tanto con gran provecho para aquel colectivo. Además, muchas revistas dentales eran publicadas por depósitos dentales y su literatura tuvo gran influencia en la odontología. La relación entre la dentistería y las compañías comerciales comenzó su declive en los comienzos del siglo XX, y entre 1930 y 1940 los Estados Unidos estuvieron en la vanguardia de la investigación básica y de la tecnología dental'. Así pues, hay que partir del recuerdo histórico de esas dos maneras de entender la odontología: ciencia y arte, con predominio acusado, que no excluyente, de cada una de ellas en uno $u$ otro modelo. Sin embargo, y siempre refiriéndonos al mundo occidental en éste análisis, procede tener en cuenta otros factores ${ }^{8}$, al menos estos tres:

A/ La odontología ha carecido de tradición docente hasta tiempos muy recientes (en España concretamente, su estudio como carrera universitaria no llegó hasta el primer año del siglo $X X)$ frente a los muchos siglos de antigüedad de las Facultades de Medicina, por no hablar de las escuelas médicas medievales. Ello condujo, en el caso de la medicina, a un progreso investigador imparable que se benefició, bien es cierto, de la «simbiosis» con la tecnología hasta los límites actuales que no encuentran paralelismo con la odontología.
La medicina de carácter universitario consolidó su hegemonía en el transcurso del siglo XIX como consecuencia de su fundamentación en las ciencias naturales (física, química y biología -las mismas que cultiva Miller, no casualmente, para proceder al mejor estudio de la odontología-). Bajo nuevas circunstancias esta medicina pasó a basarse, por primera vez en su historia, en unos supuestos conceptuales y metodológicos admitidos de forma general por encima de los desacuerdos de autores y escuelas; es decir, en una "ciencia médica» que en sus elementos fundamentales sigue aún vigente. Siguiendo un reciente y brillante estudio de Arrizabalaga9, la aportación esencial de esta nueva forma de medicina en cuanto a su conceptualización de la enfermedad fue la construcción, siempre mediante los recursos de las nuevas ciencias naturales, de una explicación de las enfermedades como trastornos corporales estructurales y dinámicos que responden a causas naturales específicas y se manifiestan a través de signos físicos, químicos y biológicos, objetivables y cuantificables en mayor o menor medida. El escenario de producción de nuevos conocimientos se trasladó, en definitiva, de la sala del hospital al laboratorio experimental, con presencia principal en Europa Occidental y en los Estados Unidos. La odontología, a la vista de la producción científica recogida en libros y revistas, ¿ha seguido el mismo camino? Sinceramente creemos que no, máxime cuando, por diversas circunstancias, en no pocos lugares optó por la vía de la independencia y se alejó de los centros de formación y asistenciales, médicos.

B/ El escaso número de dentistas con que contó la profesión en un pri- mer momento y que no se equilibró hasta bien avanzada la segunda mitad del siglo pasado, unido al aumento del nivel de vida de la población que permitió el acceso a los tratamientos dentales, hizo que la mayor parte de los dentistas dedicaran principalmente su tiempo a la práctica dental, dejando a un lado la investigación, más lenta, más ingrata -el propio Miller, paradigma del "odontólogo científico», en la cima de la profesión y con el mayor reconocimiento internacional, trabajó en unas instalaciones tan penosas en Alemania que le llevaron a abandonar el país- y menos rentable económicamente. De esta manera, la tarea de la mayoría de los dentistas consistió antes en arte que en ciencia (compruébese, por ejemplo, la escasa literatura científica que se produjo hasta las últimas décadas del pasado siglo).

C/ Un tercer factor afecta a los dos anteriores. La gran demanda profesional hizo que, como queda dicho, los dentistas se inclinaran hacia la práctica privada, quedando de ese modo los centros docentes en manos de un profesorado que no encontró grandes dificultades para acceder a los puestos académicos más elevados. Una prueba infalible son las escasas tesis doctorales que se realizaron en la primera mitad del siglo pasado (en las revistas profesionales españolas, la defensa de una tesis doctoral era noticia destacada hasta finales de los años ochenta) pues el dentista prefirió concentrarse en el ejercicio particular, más satisfactorio desde el punto de vista económico. En la actualidad, precisamente a consecuencia de la plétora profesional, el número de licenciados en odontología que acceden a los estudios de doctorado ha crecido de forma extra- 
ordinaria, lo cual llevará, en condiciones de imparcialidad, a una selección del profesorado tan competitiva como nunca se ha conocido.

Con esta nueva situación cabe esperar, paulatinamente, un crecimiento investigador importante en las diferentes parcelas de la odontología que, al menos, venga a equilibrar el acusado desfase que a nuestro juicio se sigue dando a favor de la tecnología, sobre todo en lo que se refiere a los procedimientos terapéuticos; esto es, una vez declarada la enfermedad en la cavidad bucal -sobre cuyo origen se sabe más bien poco-, las posibilidades reparadoras y rehabilitadoras son muy variadas y están bien aquilatadas, de ahí que el prestigio de la profesión se sujete mayormente en sus procedimientos terapéuticos de carga tecnológica.

Por resumirlo en una frase, no parece muy aceptable para la comunidad odontológica que más de un siglo después de la formulación de la teoría quimio-parasitaria de Miller sobre la etiología de la enfermedad de mayor prevalencia en la especie humana, la caries, la mayoría de nuestros esfuerzos para prevenirla se concentren en instruir a nuestros pacientes en el correcto cepillado de las superficies dentales para "alejar» de allí el sustrato patógeno que constituyen los hidratos de carbono.

\section{Progreso en el arte 4 la ciencia de la estomatología}

\section{Operatoria dental}

Los principios fundamentales de las terapias conservadoras dentales están sólidamente establecidas desde hace más de un siglo y se han mantenido sin apenas modificaciones a lo largo del tiempo. Los trabajos de los padres de la odontología moderna (Black, Markley, Miller, etc.) pueden ser leídos en la actualidad y no sólo con interés histórico: las propuestas cavitarias son una auténtica maravilla de diseño arquitectónico dental, los instrumentos que diseñaron se siguen utilizando en la actualidad y los fundamentos conceptuales apenas se han modificado; un claro y práctico ejemplo de ingenio al servicio de la salud dental, sin excesivos recursos técnicos ${ }^{7,10}$. Si analizamos éstos diseños cavitarios clásicos podemos establecer dos características fundamentales: a/ el diseño tan ingenioso para preparar, retener y proteger tanto la estructura dental como las reconstrucciones, con criterios, firmes asentados en la ingeniería, la dinámica oclusal y la anatomía-histología, y b/ el éxito de tales diseños, puestos en práctica millones de veces, que ha hecho que persistan, con mínimos cambios, mas bien adaptaciones, hasta nuestros días y no hayan sido superados.

Una serie de aportaciones tecnológicas han contribuido a que la evolución en operatoria dental haya tomado cuerpo. Los sistemas de corte rotatorio actuales muy poco tienen que ver con los existentes hace 100 años; las turbinas impulsadas por aire comprimido permiten alcanzar unas velocidades de giro impensables en el pasado, las fresas fabricadas con materiales que permiten un corte rápido, nítido y preciso, la refrigeración eficaz tanto de los dientes como de las fresas y la disponibilidad de fuentes luminosas potentes y dirigibles son algunos de los responsables de las adaptaciones en la mecánica operatoria a lo largo del tiempo ${ }^{11}$. En otras palabras, se corta mejor, más rápido, más preciso y de manera menos yatrógena, aunque los resultados no tienen porque ser necesariamente mejores.

Otros sistemas de preparación mecánica (ultrasonidos, láser) comienzan a utilizarse, y aunque su implantación no es muy amplia en la actualidad, sin duda se popularizarán y aumentarán sus indicaciones en el futuro.

El instrumental de mano apenas ha variado con el paso de los años. La incorporación de nuevos materiales ha permitido la construcción de instrumentos más ligeros, resistentes y teóricamente más cómodos y ergonómicos, aunque no siempre más efectivos. El oro ha dejado, prácticamente, de utilizarse y la amalgama de plata aún siendo el material de obturación más empleado, ha perdido su papel hegemónico de lustros atrás. La irrupción de las resinas acrílicas y su continuado desarrollo ha permitido, en esencia, dos cosas: el cambio de la idea de la retención mecánica (macromecánica) por la adhesión (retención micromecánica, idealmente química) y la posibilidad de disponer de materiales que mimetizan perfectamente la estética dental natural. En el aspecto práctico, y como consecuencia de los dos anteriores, ha implicado el sobreseimiento de un buen número de principios de preparación cavitaria y un gran ahorro de tejidos dentales sanos. Ahora bien, las dos bases fundamentales de la operatoria dental -oclusión y protección dental- siguen inalterables y es que mientras no sea posible la regeneración, pueden considerarse axiomas ${ }^{12}$. 
A finales de la década de los 60 comenzaron a darse los primeros pasos en odontología adhesiva, que tras sucesivas evoluciones ha sentado las bases que han llevado a la universalización de lo que se ha venido a denominar "odontología estética», cada vez más simple, resolutiva y predecible, y utilizada cotidianamente por la práctica totalidad de los dentistas. Esto ha supuesto una auténtica revolución en el campo de la odontología conservadora ya que se pueden realizar trabajos imposibles o impensables con otros materiales, a un costo asumible y con unas garantías importantes. Paralelamente la industria ha desarrollado la tecnología específica para estos materiales adhesivos y estéticos (de polimerización, de corte, de manejo, de pulido, etc.)

Durante décadas y siglos, la odontología no era, apenas, más que extracción, prótesis y operatoria dental. El tiempo ha impuesto que algunas disciplinas se independizaran, bien sea por requerir de técnicas específicas (endodoncia, periodoncia, estética) o un manejo especial (odontopediatría, odontología geriátrica, prevención). Aún así, actualmente la operatoria dental conservadora todavía ocupa la mayoría del tiempo de trabajo de la comunidad odontológica mundial ${ }^{11}$ y también de la española.

\section{Endodoncia}

Las bases conceptuales de la endodoncia permanecen invariables desde hace casi un siglo. Son tan simples como la eliminación del contenido pulpar, alcanzar el mayor grado de desinfección que sea factible (hablar de esterilización, como habitualmente se hace, es una quimera biológica) y pro- ceder al relleno más completo y hermético que sea posible. A lo largo de los años se han añadido al campo primitivo de la endodoncia otras técnicas (apicoformación, tratamiento de traumatismos, blanqueamientos, etc.) que no dejan de ser variaciones o complementos de los tratamientos convencionales de conductos. Éstos últimos apenas han cambiado en lo fundamental en 50 años. Uno de los clásicos de la endodoncia de finales del pasado siglo, Leonardo ${ }^{13}$, después de advertir que «el tratamiento endodóncico no es solamente un problema de naturaleza técnica, sino que principalmente es biológico», añade lo siguiente: «las nuevas conquistas y los nuevos conceptos deberán ser prestigiados y seguidos, porque a pesar de las honestas investigaciones, de las excelentes contribuciones y de las categóricas afirmaciones de innumerables investigadores, aún son el empirismo y el desconocimiento lo que muchas veces orientan nuestros procedimientos operatorios".

Los microorganismos responsables de la patología pulpo-periapical son múltiples, heterogéneos (gram+, gram-, aerobios, anaerobios), cambiantes, sin predominio universal y con sensibilidad antibiótica inconstante ${ }^{14}$. Además, el hecho de conocer el o los microorganismos responsables apenas tiene implicaciones terapéuticas; sea cual sea el responsable, la solución es el tratamiento de conductos (limpieza y obturación). Todo ello es más propio de una disciplina técnica que de una ciencia. Prueba de ello es que es considerado buen endodoncista -por los propios dentistas- aquél que presenta unas radiografías impecables, con varios conductos cónicos y bien sellados, aunque no tenga ni la más remo- ta idea de cuál o cuáles fueron los responsables de aquel proceso patológico; nunca al revés. Piénsalo.

Por otro lado, los medios diagnósticos siguen invariables. La radiografía manda. Se puede uno ayudar de complementos como los localizadores de ápice, tecnología informática, etcétera, pero siempre como ayuda, no sustituto. Los instrumentos apenas han variado: son limas de calibres ascendentes y descendentes, de mayor o menor conicidad y con diversos diseños de superficie. El desarrollo tecnológico nos ha brindado la posibilidad de disponer de nuevos materiales (p.e. níquel-titanio) o complementos mecánicos (sistemas rotatorios mecánicos, ultrasonidos) y más que vendrán (láser) ${ }^{15}$.

Resulta curioso observar cómo en los últimos años se está implantando la utilización de sistemas de visión e iluminación magnificados. Y es curioso porque clásicamente se ha sostenido que la endodoncia era una disciplina predominantemente táctil y ahora parece querer transformarse en predominantemente visual. Imaginamos que con tiempo se aclarará esta aparente paradoja, por otro lado perfectamente compatible.

La desinfección química de los conductos es desde hace décadas patrimonio del hipoclorito de sodio y los demás (EDTA, CHX, $\mathrm{Ca}(\mathrm{OH}$ )2, y tantos otros que ha habido y habrá). Lo mismo puede decirse de la obturación del sistema de conductos pulpares. La gutapercha ha sido y es el material de elección desde hace siglo y medio. Muchos otros materiales han quedado atrás y otros vendrán, sobre todo del fascinante mundo de los compuestos acrílicos y las resinas, pero tendrán que demostrar su bondad y su superioridad 
frente al estándar que ya ha pasado la prueba definitiva, la del tiempo. Algo similar se puede decir de los cementos selladores; se han utilizado y se utilizan muchos, lo cual quiere decir, es obvio, que no hay ninguno significativamente mejor que los demás y que nuevos productos o combinaciones seguirán apareciendo ${ }^{15}$.

La traumatología dental adolece todavía de resultados satisfactorios y predecibles. Periódicamente se proponen técnicas y protocolos, casi siempre con base empírica, aunque la anquilosis y sobre todo las reabsorciones son sumamente frecuentes.

\section{Periodoncia}

Como en tantas otras facetas de la vida, la periodoncia es una disciplina que, al mismo tiempo, puede considerarse sencillísima o altamente compleja. En esencia no consiste más que en el estudio de los tejidos de soporte dental en salud y enfermedad y de los medios y técnicas para su protección, prevención, curación y rehabilitación.

Cualquier reunión de expertos 0 workshop que se precie propone una nueva clasificación de las enfermedades periodontales; en esencia todas son similares y por supuesto ninguna es perfecta -hubiese permanecido en el tiempo-. Pero todas, es decir más del $99 \%$, las enfermedades periodontales están producidas por la placa dental en un paciente susceptible. Uno de los experimentos más reveladores de todo el ámbito odontológico demostró esta relación directa: Ios trabajos de Löe y cols $^{16}$ constituyen la piedra angular de la periodoncia científica, al mismo tiempo que demuestran que con sentido común, ideas claras y sin excesivos medios se pueden realizar magníficos trabajos científicos. La enfermedad periodontal -0 las enfermedades periodontales- es una infección oportunista cuyo inicio y severidad están determinados por la respuesta del huesped, que a su vez puede estar modulada por múltiples factores ${ }^{17}$ y la disciplina "Periodoncia» no es sino un combate contra la placa dental. La placa: millones de gérmenes de cientos de tipos en un magma orgánico-inorgánico. Se han identificado decenas de odontopatógenos, que no son los mismos para todas las personas, ni para todos los momentos, incluso ni para todas las localizaciones intrabucales. Existen miles de artículos, revistas y tratados sobre microbiología periodontal, mas no se puede sacar una conclusión directa causa-efecto, equiparable a la que ocurre en un importante número de enfermedades infecciosas del organismo (p.e. hepatitis y virus de la hepatitis). Probablemente por este motivo la periodoncia, o los periodoncistas, se han dedicado y se dedican a intentar "conseguir la situación de placa cero". Ante el diagnóstico de periodontitis, el tratamiento es, conceptualmente, único: proveer raíces lisas, sin placa y accesibles a la higiene personal motivada. Si las bolsas son poco profundas, la terapia se hace a cielo cerrado y en caso contrario con alguna técnica quirúrgica de las muchas que hay descritas. Si se trata de Prevotellas, se hace eso; si son Porphyromonas, también; si son A. actinomycetemcomitans, lo mismo y así sucesivamente.

De ningún modo los autores pretendemos banalizar la disciplina; nada más lejos de nuestras intenciones. Las publicaciones de periodoncia son las de mayor impacto entre todas las odontológicas y su nivel científico está fuera de toda duda; ahora bien, el resultado práctico es más bien discreto y lento. Sin duda está pendiente una revolución en ciernes: la genética, la molecular. Hasta la fecha la mayoría de los esfuerzos se han dirigido hacia la placa y su localización; el tercer elemento del trípode fisiopatológico, el huésped, su susceptibilidad y su resistencia, pide paso y seguro que nos deparará, pronto, agradables sorpresas ${ }^{18}$

La periodoncia clásica, es decir la que acaba de ser esbozada, queda claro que está a punto de tocar techo, si no lo ha hecho ya: los periodoncistas raspan, alisan y dominan técnicas quirúrgicas primorosamente. Poco margen para la evolución es posible en este aspecto. Ante esta evidencia se han abierto dos nuevos frentes terapéuticos: la estética y los implantes.

En una sociedad (la occidental) con unas demandas crecientes de estéti$\mathrm{ca}$, es decir de juventud prolongada, y muchas personas que pueden permitírselo, la sonrisa perfecta y la sonrisa bonita son placeres deseados. Aquí entran casi todas las disciplinas odontológicas, también la periodoncia. Aunque existen técnicas de periodoncia plástica desde hace tiempo, en los últimos años se han perfeccionado, ampliado y aumentado su predecibilidad, sobre todo gracias a los adelantos técnicos: sistemas de magnificación, iluminación y corte mejorados, materiales sofisticados, etc.

En este campo, al igual que en el de los implantes, que luego consideraremos, los avances están tantas veces más cercanos al empirismo que a la ciencia. Son numerosas las publicaciones que proponen una técnica determinada o una modificación personal de otra preexistente, basándose en unos 
pocos casos -en ocasiones uno sólo- y con un seguimiento corto, claramente insuficiente. Un buen número son abandonadas, no volviendo a haber referencias de las mismas. Casi todas carecen de investigación básica o con modelos animales, siendo los pacientes, a veces sin saberlo, auténticos conejillos de indias o perros beagle, transgrediendo normas bioéticas básicas. Y además están los pacientes tratados de forma cuasiexperimental sin publicaciones por medio o los casos desfavorables que casi nunca figuran. Por supuesto y afortunadamente, existe una significativa fracción profesional cautelosa, cuidadosa y respetuosa con la ciencia y con los que se sientan en el sillón dental.

Los implantes y la periodoncia. Hace 15 años eran minoría los periodoncistas que se interesaban por ellos, muchos incluso los que se autoexcluían de su manejo; eran periodoncistas, no más. En la actualidad todos (es decir, casi todos), incluso los que hace una década objetaban, los periodoncistas realizan la parte quirúrgica de colocación de fijaciones implantológicas. Con un criterio conceptual lógico -de lógica matemática-, la implantología dentro de la periodoncia no puede ser compatible: una cosa no puede ser ella misma y su contrario. El éxito en periodoncia se fundamenta en conseguir un complejo periodontal sano, en hueso, cemento, ligamento y encía. Por el contrario, el principal criterio de éxito implantológico es la anquilosis, es decir la total ausencia de cualquier tipo de conexión no rígida entre el hueso y la superficie del implante. Las sociedades científicas de periodoncia (actualmente de «periodoncia y osteointegración») de España y un buen número de países se han redefinido; loable y ante todo práctico, pero no consistente desde el punto de vista conceptual. Todo es opinable, aunque no igualmente fundamentado. Bien es verdad que los periodoncistas, siempre tan preocupados por el milímetro, por la conservación y la regeneración, suelen ser mucho más cuidadosos y delicados que otros especialistas.

\section{Odontopediatría}

Partiendo del paralelismo y de la relación existente entre medicina y odontología, parece lógico pensar que si existe la disciplina «Pediatría» debiera también haber su equivalente "Odontopediatría»; y así está asumido y sancionado por ese juez implacable que es el tiempo. Ahora bien, esta sencilla regla de tres, no es tan fácil de sostener con una óptica mínimamente crítica.

Bien es cierto que la pediatría posee un cuerpo disciplinario amplísimo y bien diferenciado de la medicina común, entendiendo por ella la de los adultos. Existen multitud de enfermedades, procesos y padecimientos (cientos, miles) propios o exclusivos de la infancia, muchos de ellos enormemente prevalentes y un porcentaje elevado de los padecimientos que afectan a toda la población sin marcas de edad presentan una fisiopatología, curso y tratamiento diferenciado en la edad infantil. No se puede sostener lo mismo a propósito de la odontopediatría. Se puede afirmar que la dentición decidual es diferente de la permanente; es cierto, pero los procesos mórbidos y tratamientos dentales infantiles no difieren en esencia de los aplicables a cualquier otra edad. Ciertos tratamientos del complejo pulpar o algunas opciones protésicas son casi exclusivas de la edad pediátrica, pero ni su número, ni su frecuencia, ni su complejidad son tan grandes, graves 0 específicas que requieran la necesidad de una disciplina independiente. Las enfermedades y síndromes específicos de la infancia suelen ser congénitos, y afortunadamente poco frecuentes, y su manejo suele requerir el concurso de especialistas hospitalarios y se escapan de las posibilidades de una clínica dental infantil convencional.

Si se quiere un elemento diferenciador, aunque no específico, de la odontología infantil, ese es el manejo de la conducta. Probablemente sea esa la principal razón lógica para la existencia de la odontopediatría como una especialidad académica; una causa de índole más práctica que científica.

Además, en la actualidad nos encontramos con dos circunstancias epidemiológicas: la primera es la disminución de las tasas de natalidad y del número de niños en los países occidentales. La segunda es la enorme disminución en la prevalencia, incidencia e intensidad de la caries, que es la tradicional primera causa de morbilidad dental infantil y motivo de visita al dentista en éstos mismos países. Es por ello que el espacio vital de la odontopediatría se ha extendido al campo de la prevención y sobre todo de la ortodoncia. Si hace 15-20 años eran minoría los odontopediatras que realizaban tratamientos ortodóncicos, en la actualidad son la mayoría y a los procedimientos de movilización dental se dedica una importante, a veces mayoritaria, carga de tiempo en las consultas de odontología infantil.

Por otro lado, la explosión demográfica profesional dental y la necesidad de captar y mantener clientes hace que casi todos los dentistas generales realicen la mayoría de los tratamientos den- 
tales infantiles y no es descabellado pensar que en un futuro no muy lejano, la figura del odontopediatra quede relegada a la de un(a) dentista especializado en el manejo de niños inquietos o problemáticos y al tratamiento de procesos poco frecuentes y que dedique buena parte de su jornada laboral a los tratamientos de ortodoncia.

\section{Odontología preventiva}

El comienzo de la medicina como ciencia supuso la búsqueda de la etiología de las enfermedades. Lo mismo puede decirse en el campo de la odontología. Dejando atrás teorías que hoy suenan casi folclóricas (vermicular, humoral, etc.), el origen microbiano de las enfermedades dentales más prevalentes, la caries y la enfermedad periodontal, está fuera de toda duda. Centrándonos en la caries, que es la primera causa mundial de morbilidad, hay que decir que lo que hoy se sabe es mucho, pero no añade demasiado a los conceptos establecidos hace más de 50 años. La prevención de los problemas bucales, específicamente los dentales, y en concreto de la caries, se basa en tres pilares: higiene, hábitos alimenticios y fluoruros. Aunque están descritas multitud de técnicas de cepillado, excepto en algún caso concreto, ninguna de ellas es significativamente mejor 0 peor que las otras, siempre que se realicen correctamente. Existen, han existido y existirán cientos de diseños de cepillos dentales, todos básicamente similares, y respetando unas normas mínimas de calidad, con validez tan equiparable como variable según los estudios 0 quién los financie.

La relación dieta-caries es conocida y está demostrada desde hace déca- das, y pocas novedades significativas se han producido desde entonces. Realmente el tema no da para mucho más; otra cosa es que se sigan o no las recomendaciones dietéticas.

En cuanto a los fluoruros, desde su descubrimiento, reconocimiento y popularización como eficaz medida anticaries (hace ya más de 60 años), en esencia lo único que se ha ido modificando ha sido el vehículo (líquido, gel, comprimido, colutorio, dentífrico, barniz), las sales de fluoruro (de sodio, de aminas, MFS, combinaciones, etc.), los regímenes de aplicación (diario, semanal, mensual, etcétera) y las concentraciones (a la baja).

Algo similar puede decirse de la prevención de las enfermedades periodontales: instrucciones para el control mecánico de la placa y en algunos casos químico. Y lo mismo podemos observar al considerar la evolución en la prevención de otros problemas dentales -maloclusiones, fracturas, prótesis- y no dentales -prevención del precáncer y cáncer-.

Aunque es una generalización, y ello siempre supone admitir un cierto grado de error, todos los conceptos preventivos que aparecen en un buen manual de hace más de 20 años son perfectamente aplicables en la actualidad, con mínimas variaciones ${ }^{19}$. Probablemente ya se haya alcanzado un notable estadío de desarrollo, la cosa no dé para más, ambos, o haga falta un cambio radical de punto de vista.

Otro tanto puede decirse de la odontología comunitaria. El arraigo de los conceptos de comunidad, grupos, atención primaria, etc., a finales de la década de los 70 , ha producido una auténtica explosión de esta disciplina, aunque desde el punto de vista odon- tológico bien pudiera considerarse simplemente como la aplicación de los conceptos de la odontología preventiva no a los individuos aislados sino a las comunidades. Su valor práctico es innegable, con un fabuloso descenso en los indicadores de prevalencia e intensidad de las caries y en menor medida de la enfermedad periodontal. Aun a fuerza de ser injusto por la simplificación, desde el punto de vista práctico, nos ha aportado básicamente dos cosas: un piélago de estudios epidemiológicos y multitud de estudios de campo sobre comunidades y grupos humanos en prevención bucodental.

Por otro lado la odontología preventiva es una disciplina académica básica y esencial, pero sin aplicación clínica profesional directa; que sepamos no existe ninguna clínica dedicada exclusivamente a la prevención dental. Sin embargo todas las disciplinas clínicas utilizan diariamente los contenidos preventivos. La odontología comunitaria es patrimonio casi exclusivo de los sistemas públicos de salud.

\section{Ortodoncia}

La disciplina "Ortodoncia» emergió paralelamente a las artes de conservación dental sin derivarse directamente de las mismas, bien al contrario, por ejemplo, de la endodoncia. Las motivaciones iniciales se mantienen en la actualidad: recolocar los dientes para mejorar la función y, sobre todo, la estética.

En esencia la ortodoncia no es otra cosa que la aplicación práctica de la tercera ley de Newton. Con el tiempo, la experiencia y, claro está, el progreso tecnológico, se han ido diseñando y optimizando las maneras de sujetar y mover los dientes de la forma desea- 
da (fijación y aplicación de las fuerzas sobre los dientes con el vector deseado) y lograr que los movimientos y efectos indeseables se reduzcan en lo posible (anclaje y estabilidad). Simplificando, no es más que eso.

El desarrollo tecnológico ha permitido que lo antes comentado pueda hacerse de formas cada vez más sencillas, rápidas y predecibles. Hasta hace medio siglo los sistemas de sujección dental eran complicados, molestos, antiestéticos y bastante yatrógenos. La aparición de sistemas adhesivos y las mejoras en la industria micrometalúrgica proporcionaron el arrinconamiento de los embandados exhaustivos, las soldaduras generalizadas, y la universalización de los brackets (una de las pocas palabras sin traducción reglada), cada vez más pequeños, precisos y fáciles de utilizar. También se han comenzado a utilizar materiales no metálicos (plásticos, cerámicas, siliconas), más estéticos y los aparatos invisibles (es decir, menos visibles).

Por otro lado, los elementos generadores de fuerzas y momentos, los alambres y los arcos, han mejorado enormemente. Los nuevos materiales, muchos con casi impensables propiedades, los diseños preformados, etcétera, han permitido que los tratamientos sean cada vez más predecibles y universales, además de reducir el tiempo de consulta y el número de visitas.

La mayor revolución conceptual en la centenaria ortodoncia deriva de la observación crítica y del análisis detallado de un puñado de "oclusiones ideales» y la inferencia de cómo poder alcanzarlas desde cualquier otro punto de partida no ideal. Andrews ${ }^{20}$ definió las llaves de la oclusión ideal y diseñó un sistema de brackets con unas caracte- rísticas específicas en la base que, aplicando los arcos correspondientes, nos acercarían mucho a esa oclusión óptima. Esto es la base de los denominados «sistemas preajustados». Muchos clínicos y autores han descrito y comercializado sus «prescripciones» (así las denominan, como si fuesen recetas médicas) que son todas básicamente similares, con unos grados más o menos de peralte -rotación o inclinación-. Como perfectamente afirma un reciente artículo"1 "una oclusión objetivo es una definición cultural, creada por el hombre, que se apoya en buenas razones y que lleva muchos años entre nosotros... la perfección de esta oclusión no se da en la naturaleza». La simplificación y estandarización de la mecánica y los nuevos materiales, especialmente los denominados "con memoria», han traído como consecuencia práctica la universalización de la ortodoncia; si hace 20 años era patrimonio de unos pocos profesionales, ahora la mayoría de los dentistas pueden ofrecer tratamientos correctores para un elevado porcentaje de los casos y hacerlo de forma efectiva y eficiente.

En las Escuelas y Facultades nos han enseñado que lo fundamental en ortodoncia era el diagnóstico. Curiosamente, éste tampoco ha sufrido cambios en su naturaleza durante décadas: estudio de modelos, de imágenes y de radiografías. El desarrollo tecnológico, especialmente la revolución informática y digital, ha permitido que esta triada diagnóstica pueda ser más completa, sobre todo más impactante - imágenes en movimiento, simulaciones informáticas, previsiones, líneas y colores ilimitadospero un milímetro sigue siendo un milímetro y el SNA-SNB sigue estando en el padrenuestro de la ortodoncia. Los sistemas cefalométricos son casi tantos como autores los estudiaron. Todos aportan algo y todos tienen limitaciones, de manera que ninguno de ellos arrincona a los demás y con todos o con la mayoría se puede obtener un diagnóstico competente.

Los conocimientos acerca del crecimiento facial, del movimiento dental y de la biología ósea han progresado mucho, aunque su aplicación práctica siga siendo muy limitada. En la práctica, nos impresionamos cuando un ortodoncista nos muestra sus casos en varias pantallas, con antes y después, llenas de componentes y artilugios, y con unos resultados fenomenales. Todos, creo, nos fijamos en la mecánica y en los trucos, pero nadie o casi nadie nos comenta o se interesa por lo que pasó en el micromundo oseoperiodontal. Todos, pacientes y dentistas, pensamos que un buen ortodoncista es aquel que consigue buenos resultados. Menos importa que conozca o controle las bases biológicas de los movimientos. Dicho de otra manera, un buen ortodoncista ha de ser un buen mecánico con una fundamentación biológica básica; un profundo conocedor de la biología del movimiento dental y óseo, pero con unas manos torpes nunca lo será, ni a la vista de los pacientes, ni los compañeros dentistas les derivarán los suyos.

\section{Prótesis dental}

La prótesis dental es tan antigua como las civilizaciones clásicas. Su fundamento está entre la lógica y el instinto: cuando te falta algo necesario hay que intentar suplirlo de la mejor forma posible. No creemos que los sumerios o los egipcios fuesen más torpes o más tontos que los dentistas 
actuales; probablemente la diferencia estribe en las posibilidades técnicas y tecnológicas, radicalmente diferentes.

Se puede considerar que la prótesis dental es la zona de encuentro entre unos conceptos básicos de ingeniería (selección y diseño de pilares y pónticos, resistencia de los mismos y distribución de fuerzas) y otros de biología (estructura dental y periodontal, respeto óseo y mucoso). Y puede ser fija o extraible, sobre dientes, mucosas y recientemente sobre implantes, pero los conceptos fundamentales están consolidados desde hace lustros. Un buen libro de prótesis de hace 30 años puede estar perfectamente vigente en la actualidad, poniendo al día las opciones y posibilidades tecnológicas, que no las técnicas.

Los modernos materiales permiten por un lado mayor respeto a las estructuras biológicas y por otro poseen unas propiedades mecánicas y especialmente estéticas prácticamente naturales. Esto es fruto del avance tecnológico, tanto de la manipulación dental -instrumentos de corte precisos y específicos, refrigeración, iluminación, magnificación-, como de los materiales protésicos -nuevas aleaciones, porcelanas, sistemas adhesivos, aplicaciones informáticas-, mas poco o nada de nuevos conceptos básicos. La prótesis extraible, ya sea parcial o completa, es exactamente igual hoy que hace más de un siglo, con la única salvedad de las mejoras que se han producido en este tiempo en los materiales.

Mención aparte merecen los implantes dentales que han supuesto un auténtico punto y aparte en el mundo de la odontología en general y de la prótesis en particular. Los implantes dentales permiten una ampliación con- ceptual nueva: las prótesis (fijas) no se apoyan en los dientes, sino en un elemento artificial que se comporta de un modo similar al diente. No obstante, toda la prótesis sobre implantes ha tomado su fundamentación de la prótesis dentosoportada clásica, con una variación conceptual: los dientes se mueven, poco, pero se mueven; los implantes, si lo hacen, malo. Hasta la fecha se ha adoptado una solución salomónica al respecto, no conectar dientes con implantes. Por el resto, los fundamentos mecánicos, si no son iguales, al menos son equiparables.

\section{Medicina y Cirugía oral}

En España, y en tantos otros países occidentales, la licenciatura en «Medicina» lo es en realidad en "Medicina y Cirugía». Por este motivo consideramos ambas facetas juntas, como dos ramas del mismo tronco.

De algún modo se puede afirmar que la medicina oral se ocupa del estudio de todos los componentes del aparato estomatognático diferentes de los dientes. Éstos últimos representan, aproximadamente, el $20 \%$ de la superficie de la boca y anexos, aunque en la práctica odontológica habitual supongan más del $95 \%$ de la carga del trabajo. El estudio de los procesos y enfermedades que afectan a los tejidos blandos y duros del aparato estomatognático y las manifestaciones orales de los procesos generales es casi tan amplio como desconocido por la generalidad de los practicantes, que con tanta frecuencia derivan estos pacientes a otros especialistas (ORL, dermatólogos, internistas, cirujanos maxilofaciales). Además de amplio podemos calificarlo como de constante evolución, equiparable al de la medicina general y sus especialidades. En los últimos años los progresos en el conocimiento etiológico, patogénico y terapéutico han hecho variar el diagnóstico, pronóstico y la calidad de vida de tantos procesos y pacientes, y ello ha sido más el fruto de los progresos en las ciencias básicas -histopatología, fisiología, bioquímica, genética molecular, farmacología- que de un desarrollo tecnológico específico, que también ha tenido su papel, bien al contrario de las novedades odontológicas.

Bastante de lo mismo puede considerarse al referirnos a la cirugía oral. Son muy pocas las técnicas e instrumentos introducidos en los siglos XIX Y $X X$ o que se hayan modificado sustancialmente ${ }^{22}$. La mayoría de los avances y progresos provienen del mejor y más completo conocimiento de los procesos y enfermedades $y$, por ende, de la racionalización de su abordaje. También es cierto que los últimos años han incorporado mejoras notables en los procedimientos terapéuticos operatorios -microcirugía, endoscopia, láser-. Al igual que ocurre con la cirugía que es una disciplina científica puramente médica que utiliza prioritariamente entre otras modalidades terapéuticas la intervención quirúrgica, la cirugía oral podría considerarse una versión de la medicina oral con posibilidades de tratamiento intervencionista, y su evolución deriva esencialmente del mejor conocimiento de los procesos mórbidos, además de un desarrollo tecnológico paralelo.

\section{Otras materias académicas}

Existen otras materias académicas que no son puramente clínicas pero que fundamentan, permiten o ayudan a la buena práctica clínica; tales 
pueden ser la radiología o la ciencia de los materiales odontológicos. Su esencia es, básicamente, tecnológica y su desarrollo reciente ha sido espectacular. Por ejemplo, la radiología ha entrado de lleno en una era digital, con mayores prestaciones, menos efectos secundarios y todas las casi inimaginables posibilidades que ello ofrece: tratamiento de imágenes, predicciones, teleodontología, etc.

Exactamente lo mismo cabe decir de los materiales odontológicos, cada vez más sofisticados, compatibles, estéticos y generalmente resolutivos. El progreso en la ciencia de los materiales odontológicos ha permitido el avance terapéutico en todas las disciplinas dentales; también es posible pensar lo contrario, las necesidades clínicas han requerido el diseño y desarrollo de materiales adaptados a las mismas. Convengamos que esta explosión tecnológica es un tanto desordenada y que además de razones técnicas también participa de otras comerciales. Como ejemplo, podemos comentar que en la última megaexposición comercial odontológica española (Expodental 2004) se comentó que al mercado español salen una media de cinco productos diarios, cifra imposible de digerir por el sector y que paralelamente supone la desaparición de cientos de ellos al cabo de poco tiempo.

\section{Implantes}

Los autores no dudamos que en poco tiempo la implantología será una especilidad odontológica independiente.

La implantología tiene cientos de años a sus espaldas, con muy pobres resultados hasta mediados del siglo pasado en que comenzó, tímidamen- te, la implantología moderna, aunque el verdadero punto de inflexión lo marcan los trabajos de Bränemark ${ }^{23}$ de hace 30 años que constituyen el despegue de lo que podemos denominar implantología predecible o actual.

Desde un punto de vista conceptual, la implantología propone algo radicalmente diferente al resto de la odontología: no se trata de cuidar o reparar un diente, sino que se pretende hacer aparecer una raíz y un diente allí donde no existe más que hueso. Con esta visión, no estaríamos ante un campo odontológico, sino más bien metaodontológico. Dejando a un lado disquisiciones filosóficas, si existe algo verdaderamente nuevo en odontología en las últimas décadas, eso es, sin duda alguna, la implantología.

La implantología consta de dos procesos combinados, aunque perfectamente separables. Por un lado está la colocación de las fijaciones y por otro la construcción de piezas sobre las mismas. La última utiliza los conceptos de la prótesis dental convencional -confección de estructuras y piezas, oclusión- con la salvedad del anclaje sobre pilares artificiales rígidos osteointegrados. Es la primera parte, es decir la colocación de las fijaciones, los implantes propiamente dichos, lo auténticamente novedoso y revolucionario, hasta el punto que algunos se han atrevido a hablar de una tercera dentición, sin duda llevados por un entusiasmo cegador; la naturaleza lo que da, lo da a todos y además de balde.

como actividad nueva de resultados contrastados y predecibles, de gran impacto social y económico, le han surgido novios doquier. Cirujanos orales y maxilofaciales, periodoncistas, cirujanos plásticos, ORL, odontó- logos y estomatólogos generales reclaman para sí su pedacito de gloria; y todos con razones legítimas.

También está la industria. Si hace 15 años apenas había unos pocos fabricantes y un número limitado de opciones, hoy en día son cientos y miles, respectivamente. Ocurre que son todos esencialmente iguales: un tornillo de titanio con espiras externas e internas. Los hay más cortos y más largos, más o menos anchos, con más o menos espiras a veces más y a veces menos profundas, más cónicos o cilíndricos y sus combinaciones. Y lo mismo puede decirse de la técnica, lo más atraumática y aséptica posible, intentando conseguir la máxima superficie de contacto entre los implantes y el hueso. Está claro que hay casos favorables y sencillos y otros altamente complejos y de peor pronóstico, pero ninguno escapa a los principios básicos.

Por otro lado y por tratarse de un campo nuevo, las innovaciones son constantes y hacen que surjan continuamente diseños, protocolos y criterios, muchos de los cuales quedan obsoletos o desfasados en poco tiempo. Sirva como ejemplo que a principios de los 90 se recomendaban y utilizaban casi exclusivamente implantes de rosca totalmente lisa e implantes impactados; ambas posibilidades prácticamente han desaparecido en la actualidad. Quiere ello decir que el desarrollo comercial y también el tecnológico avanza mucho más deprisa que la investigación científica clínica, por definición lenta. Esto produce la paradoja de que muchos así denominados "sistemas de implantes" se recomienden, incluso se utilicen con cierta asiduidad para luego caer en el más absoluto olvido. Ello justifica la 
existencia de una ingente cantidad de artículos, normalmente en publicaciones cuasidivulgativas, pero también en otras consideradas más serias desde el punto de vista científico, con series cortísimas, seguimientos claramente insuficientes y con notables errores de diseño $y$, sobre todo, de inferencia. Además existe otro factor destacable. Son muchos los estudios que refieren algún grado de significación estadística y eso no tiene porque implicar directamente significación clínica. Con la debida cautela, hay algunos casos en que podría pensarse en experimentación sobre pacientes y que estarían en ese terreno cenagoso que separa la ciencia de la ciencia-ficción.

Imaginamos que, al igual que ha ocurrido antes con otras disciplinas odontológicas y médicas, el tiempo será el verdadero juez y que se simplificarán, unificarán y protocolizarán las opciones técnicas, tecnológicas y comerciales y se producirá una auténtica universalización (globalización) de la implantología. Por supuesto quedarán especialistas de referencia, cada vez más resolutivos, eficaces y efectivos, y seguramente la implantología será una materia curricular más en los planes de estudio odontológicos.

\section{Odontogeriatría}

Sin duda nos encontramos ante una especialidad emergente. En la actualidad no se estudia independientemente, aunque es altamente previsible que se haga en un futuro inmediato. En realidad no existe una razón diferenciadora específica que justifique su existencia autónoma; incluso está perfectamente demostrado que la mayoría de los cambios que ocurren en la boca de los ancia- nos no se deben al envejecimiento en sí, sino más bien a los efectos secundarios 0 acumulativos de enfermedades sistémicas, fármacos, radiaciones, etc. ${ }^{24}$ Pero también es cierto que existen razones de peso para su independencia tanto académica como profesional: a/ epidemiológicas: envejecimiento de las poblaciones, aumento de la cantidad y calidad de vida; b/ bibliográficas: miles de artículos, decenas de revistas y libros especializados en este colectivo; c/ comparativas: si la geriatría es una especialidad médica reconocida, también podría serlo la odontogeriatría. Las mismas razones que asisten la existencia de la odontopediatría justificarían la odontología geriátrica, sin olvidar que otras razones "académicas» han contribuido a la consolidación de determinadas disciplinas nuevas como esta; es decir, la creación de pequeños reinos de taifas donde un responsable puede reinar a placer $-y$ con contribuciones significativas en este campo, no lo discutimos- ya que los grandes reinos están ocupados y con muchos pretendientes en la lista de espera preceptiva.

Desde un punto de vista objetivo, las alteraciones, trastornos y enfermedades de los dientes y la boca de los ancianos no difieren demasiado de lo que acontece en los adultos, excepto en prevalencia y severidad. Al igual que consideramos al referirnos a la odontología pediátrica, la razón más consistente para su consideración académica y profesional aislada lo constituye la personalidad del grupo de edad, entendiendo por ello el manejo de la conducta, las discapacidades, la morbilidad, la polifarmacoterapia, etc.

\section{Otras próximas materias académicas}

Muchos de los razonamientos empleados previamente para justificar el carácter distintivo e independiente de la implantología y de la odontología geriátrica podrían aplicarse para otras disciplinas. Ponemos como ejemplo la odontología legal y forense, la oclusión-ATM y la gestión-marketing.

La primera de ellas es una actividad en franca expansión, bien probablemente por la creciente complejidad del mundo actual y del odontológico en particular, pero principalmente por las intrínsecas características histológicas de las estructuras dentales. En resumen, la tan citada "Caja negra" de nuestro organismo, esto es, la dentadura resuelve problemas de identificación cadavérica como ningún otro órgano puede hacer; de ahí que cada vez se reclame con mayor insistencia la presencia de peritos odontológicos. Peritajes, valoración de daños, reclamaciones, etc., forman parte del universo odontológico presente y futuro, tan lleno de luces como de sombras. Todo ello requiere, no puede ser de otro modo, de una disciplina basada en la evidencia científica que regule con bases sólidas materias ciertamente delicadas. Lo mismo ha ocurrido hace ya tiempo en un espejo donde es conveniente de vez en cuando mirarse, la medicina.

Todo el sistema de relación entre los maxilares superior e inferior es ciertamente complejo. Existen dos articulaciones condíleas que funcionan coordinadas e influyendo en todos sus movimientos hasta 16 elementos altamente heterogéneos y de superficies irregulares que se oponen a otros 16 elementos en el maxilar antagonista (oclusión). Para complicarlo más, los 32 elementos no están soldados rígidamente, sino articula- 
dos (gonfosis) con los huesos maxilares. Y todavía más, los dientes tienen dos generaciones, y se gastan, se rompen, se pierden y se reponen. Todo ello coordinado por un montón de músculos, con delicados sistemas de fijación ligamento-tendinosos y bajo la atenta mirada del trigémino. Sin duda un mundo apasionante que merece un estudio específico y diferenciado. Algunas sociedades odontológicas hace tiempo ya lo predican.

La gestión y el marketing odontológico, aunque no son sinónimos, participan de un elemento común diferenciador y novedoso: la odontología además de producir salud, lo cual es obvio, también debe producir riqueza. Es probable que hace 20030 años, con un título, un cartel y las cuatro reglas fuese suficiente. A todas luces hoy no. El número de dentistas se ha multiplicado por $X$, el de futuros dentistas por $Y>X$, mientras que la demanda es de $Z<X$. De un modo simplista es así. Otros Io han escrito y fundamentado mejor ${ }^{25}$.

Las técnicas de venta y gestión de productos o servicios se aplican a casi todo en la actualidad, también a la odontología. Los autores no pueden imaginar otra cosa que su estudio reglado dentro de los planes de estudio universitarios correspondientes.

\section{Multidisciplinarios con objetivo concreto o específico}

Existen otras actividades dentales que demuestran la contínua evolución de la profesión y su relación con las necesidades y demandas actuales de la población. Incluimos en este grupo la estética dental, la odontología microscópica, la odontología del deporte y el láser dental; probablemente podrían considerarse otras, pero estimamos que éstas son las que están más implantadas, hasta el punto de existir cursos, congresos, sociedades científicas y literatura específica en estos campos.

La odontología estética no es sino el resultado de agrupar técnicas y actividades con el nexo común de un objetivo determinado, el estético. Por ello incluye opciones de la mayoría de las especialidades clínicas -conservadora, prótesis, ortodoncia, periodoncia, implantes- coordinadas para alcanzar una sonrisa más bella y armónica. Los objetivos estéticos no son, ni mucho menos, nuevos, pues ya habían alcanzado un nivel altísimo en la antigüedad grecorromana y posteriormente en el renacimiento. Cierto es que entonces se referían esencialmente al cuerpo y si se quiere también a la cara. Los cánones estéticos clásicos apenas tienen referencias dentales, ni en pintura ni en escultura, bien probablemente por las limitadas posibilidades de actuar sobre los dientes en contraposición de las milenarias opciones de modelaje estético del resto del organismo: deporte, vestido, peluquería, joyería, etc. La posibilidad de modificar la estética dental de un modo previsible es ciertamente reciente y esto es así simplemente porque el desarrollo técnico y tecnológico lo ha permitido y no porque antes no se supiera qué es lo que habría que hacer; simplemente carecían de medios para conseguirlo. En la actualidad se pueden lograr resultados espectaculares y para casi todas las situaciones y condicionantes. El futuro, con un desarrollo tecnológico multiplicado, permitirá ampliar todavía más el abanico de posibilidades, hacerlas cada vez más sencillas y al alcance de más practicantes y pacientes.
La utilización de magnificación óptica tiene bastantes años de evolución en diferentes especialidades médicas -ORL, oftalmología, neurocirugía- y también ha comenzado a utilizarse en distintos campos odontológicos. Es, por tanto, la llamada «odontología microscópica» una actividad multidisciplinar con un nexo común: ver más grande y mejor iluminado y de esa manera poder conseguir mejores y más precisos resultados.

Exactamente lo mismo puede decirse de la odontología con láser: un avance tecnológico permite disponer de una herramienta de corte y coagulación limpia, potente y estéril, aunque lamentablemente no universal. Tanto la odontología con láser como la odontología microscópica se justifican por la utilización de un notable progreso técnico y tecnológico en distintas facetas odontológicas $y$, de alguna manera, reclaman su parcela docente autónoma. No se puede olvidar que existen libros y publicaciones específicas y sociedades científicas que lo respaldan.

La odontología del deporte es otro campo pluridisciplinar, no siendo su nexo cohesivo ni una disciplina clínica diferenciada, ni un avance técnico concreto, sino una particularidad de la boca de su población diana: que practica algún deporte. La medicina del deporte es actualmente, y desde hace muy poco, una especialidad regulada por el sistema de especialización MIR; existen másteres universitarios reconocidos y profesionales que se dedican a la medicina deportiva, por lo que es imaginable que en un (poco) tiempo la medicina del deporte será una especialidad médica con un espacio académico y laboral propio como cual- 
quier otra. La odontología, como tantas otras veces, sigue un proceso paralelo, más tardío. Es opinable si la odontología del deporte tiene un cuerpo doctrinal suficientemente diferenciado o suficientemente prevalente para justificar su estudio individualizado, pero creemos que dada la especialización en todas las artes odontológicas y su creciente sofisticación y tecnificación, es muy probable que pueda ser una materia odontológica más. El bagaje bibliográfico, las demandas de los deportistas, la población y los dentistas, y, por supuesto, el tiempo implacable, darán la solución.

\section{Conclusiones}

- La odontología actual ha alcanzado un impresionante grado de progreso y capacidad resolutiva.

- El perfil académico y profesional de la odontología ha cambiado y cambiará bastante en los últimos años y en el futuro.

- La mayor parte del progreso en las disciplinas dentales es atribuible al desarrollo tecnológico, habiéndose modificado muy poco las bases conceptuales de la odontología.

- El perfil actual del dentista está más cercano al de un técnico que trabaja para la salud que al de una profesional de una ciencia médica.

\section{Bibliografla recomendada}

Para profundizar en la lectura de este tema, el/los autor/es considera/an interesantes los artículos que aparecen señalados del siguiente modo: *de interés ${ }^{*}$ de especial interés.

1. Sackett DL. Medicina basada en la evidencia. Como ejercer y como enseñar la MBE. Madrid: Churchil Livingstone, 1997.

2. Hoffmann-Axthelm W. History of Dentistry. Chicago: Quintessence books, 1981

3. Ortega y Gassett J. La revolución de las masas. Madrid: El Pais SA. Clásicos del siglo XX, 2002: 150 .

4. RAE. Diccionario de la lengua española. $21^{\mathrm{a}} \mathrm{ed}$. Madrid: Espasa-Calpe SA, 1992.

5. BOE. Ley 10/1986. Madrid: BOE, 20 de Marzo de 1986.

6. Carranza F, Shklar F. History of Periodontology. Canadá: Quintessence books, 2003.

7. Simon WJ. Higlights of operative dentistry in America, 1859-1959. Int Dent J 1960;2:17382.

8. Sanz J. Historia General de la Odontología Española. Barcelona: Masson, 1999.

9. Arrizabalaga J. «Medicina basada en la evidencia»: ¿Cambio de paradigma o nuevo etiquetado?. En: La medicina ante el nuevo milenio: una perspectiva histórica. Cuenca: Ediciones de la Universidad de Castilla-La Mancha, 2004: 743-55.

10. Sturdevant CM, Barton RE, Sockwell CL, Strickland WD. Arte y ciencia de la operatoria dental. Buenos Aires: ed. médica panamericana, 1986.

11*. Seldin LW.(por el oversight committee, American Dental Associationof dentist report). El futuro de la Odontología. J Am Dent Assoc (ed. esp) 2002;5:9-21.

Análisis completo, realizado por un comité de expertos de la ADA, referido a la situación actual de la odontología en casi todos sus aspectos y previsiones para el futuro inmediato.

12*. Salsench J. Los retos de la odontología clínica. (Editorial). J Am Dent Assoc (ed. esp) 2002;5:9.

Editorial realista y directa que postula que el progreso técnico actual de la odontología no puede ni debe eludir los principios básicos en los que se sustenta la disciplina, cada vez más sofisticada.

13. Leonardo MR, Leal JM, Simoes Filho AP. Endodoncia. Tratamiento de los conductos radiculares. Buenos Aires: ed. médica panamericana, 1983.

14. Siqueira JF jr. Taxonomic changes of bacteria associated with endodontic infections. $J$ Endod 2003;29:619-23.

15*. Canalda C, Pumarola J, Berástegui E. Actualización en endodoncia 2003. Arch Odontoest 2004:20:347-58.

Artículo de revisión, de una serie que toca casi todas las facetas odontológicas y que anualmente se publica en la revista mencionada. Suelen ser muy completos, actualizados y concisos.

16*. Löe H, Theilade E, Jenson SB. Experimental gingivitis in man. J Periodontol 1965;36:17782

Artículo básico, sencillo y revelador que demuestra cómo la placa está en la base de las enfermedades periodontales. Uno de los pilares de la periodoncia científica.

17. Hugoson A, Ljungquist B, Breivik T. The rela- tioship of some negative events and psycological factors to periodontal disease in adult Swedish population 50 to 80 years of age. J Clin Periodontol 2002;29:247-53.

18. Abandar JM. Global risk factors and risk indicators for periodontal diseases. Periodontology 2000 2002;29:177-206.

19. Katz S, McDonald JL, Stookey GK. Odontología preventiva en acción. Buenos Aires: ed. médica panamericana, 1986.

$20^{*}$. Andrews LF. The six keys to normal occlusion. Am J Orthod 1972;62:296-309. Artículo fundamental, origen del desarrollo de los aparatos ortodóncicos de arco recto.

21. Martínez-Asúnsolo P, Plasencia E. Las 6 llaves de la oclusión de Andrews en 32 modelos con oclusiones ideales no tratadas. Rev Esp Ortod 2004;34:235-44.

22. Siessegger M, Mischowski R, Neugebauer J, Krug B, Zöller J. Extracción quirúrgica de dientes luxados de forma yatrogénica. Quint Int (ed esp) 2004;17:235-41.

23*. Bränemark PI, Albrektsson T, Zarb GA(ed). Tissue integrated prostheses. Osseointegration in clinical dentistry. Chicago: Quintessence, 1985 .

Exposición y desarrollo de los fundamentos de la implantología actual, predecible.

24. Holm-Pedersen P, Löe H. Textbook of geriatric dentistry. $2^{\mathrm{a}}$ ed. Copenhagen: Munksgaard, 1996.

25. Cuenca E. La demografía profesional en España: cabalgando un tigre. (Editorial). RCOE 2004:9:271. 